\title{
Novel technological possibilities for growth of GaAs autoepitaxial films, and properties of Gunn diodes made on their basis
}

\author{
A.E. Belyaev ${ }^{1}$, A.V. Bobyl ${ }^{2}$, N.S. Boltovets ${ }^{3}$, V.N. Ivanov ${ }^{3}$, R.V. Konakova ${ }^{1}$, \\ S.G. Konnikov', Ya.Ya. Kudryk', E.P. Markovskiy ${ }^{1}$, V.V. Milenin ${ }^{1}$, E.M. Rudenko ${ }^{4}$, \\ G.F. Tereschenko², V.P. Ulin², V.M. Ustinov², G.E. Tsirlin ${ }^{2}$, A.P. Shpak ${ }^{4}$ \\ ${ }^{I} V$. Lashkaryov Institute of Semiconductor Physics, NAS of Ukraine, 41, prospect Nauky, 03028 Kyiv, Ukraine \\ ${ }^{2}$ A.F. Ioffe Physico-Technical Institute, RAS, 26, Politekhnicheskaya str., 194021 St.-Petersburg, Russia \\ ${ }^{3}$ State Scientific \& Research Institute “Orion”, 8a, Eugene Pottier str., 03057 Kyiv, Ukraine \\ ${ }^{4}$ G.V. Kurdyumov Institute of Metal Physics, NAS of Ukraine, \\ 36, Akademika Vernadskogo Blvd., 03680 Kyiv, Ukraine
}

\begin{abstract}
The $n^{+}-n-n^{+}-n^{++}$-GaAs epitaxial structures were MBE-grown on porous nanostructured and traditional (standard) heavily doped $n^{++}$-GaAs substrates. On their basis, we fabricated the Gunn diodes generating power output in the 44-59 GHz (first harmonic) and 101-104 GHz (second harmonic) frequency ranges. For both harmonics, the power output of the Gunn diodes grown on porous substrates was shown to be from 20 to $30 \%$ higher than those grown on the flat ones.
\end{abstract}

Keywords: porous $n^{++}$-GaAs substrate, epitaxial structures, the Schottky barrier, the Gunn diode, ohmic contact.

Manuscript received 27.07.05; accepted for publication 25.10.05.

\section{Introduction}

Gallium arsenide is the best studied material of the III-V semiconductor compounds. It has found a wide application in many areas of electronics. The GaAs active elements, such as the Gunn diodes, IMPATT diodes, pin diodes, field-effect transistors, etc., are more efficient than silicon ones when solving various problems of microwave electronics. However, up to now the development of GaAs element base involves two problems: production of epitaxial layers of perfect structure and formation of heat- and radiation-tolerant contacts to them (just as in the case of $\mathrm{Si}$ microwave devices, especially those intended for millimeter waves).

The first problem is being solved by growing the epitaxial layers using the molecular-beam epitaxy (MBE) technique (mainly for research works) or competing the metallic-organic chemical vapor deposition (MOCVD) technique (for various purposes, including large-scale production) that provides obtaining the submicron layers with controlled parameters. However, these techniques as well as the classical liquid-phase epitaxy (LPE) and vapor-phase epitaxy (VPE) do not enable one to form unstrained (or slightly strained) epitaxial layers. At the same time, it is known that even insignificant microdeformations in the active areas of device structures lead to development of degradation processes in them.

It was shown in a number of works performed at the A.F. Ioffe Physico-Technical Institute of Russian Academy of Sciences in the late 1990s that it is possible to reduce the level of intrinsic strains (IS) and defect density in epitaxial structures, if (contrary to the traditional techniques) they are grown on porous substrates [1-3]. In this case, the porous substrate takes over elastic deformations (that appears at all stages of film growth, involving cooling) and ensures dislocation sink. Up to now, the technique of porous substrates formation has been developed for III-V materials ( $n$-GaAs, GaP, $\mathrm{GaSb}, \mathrm{InP}, \mathrm{GaN}, \mathrm{Al}_{x} \mathrm{Ga}_{1-x} \mathrm{As}$ and $\mathrm{Ga}_{x} \mathrm{In}_{1-x} \mathrm{As}$ ) as well as for a number of other semiconductors. Epitaxial layers with perfect structure and the lowest IS level are grown on the porous GaAs and InP substrates $[1,2,4]$.

The second problem is being solved by usage of barrier-forming and buffer layers on the basis of amorphous composites (alloys of interstitial phases) or by choosing the corresponding refractory metals $[5,6]$.

In this work, we made an attempt of using the $n$ GaAs autoepitaxial films grown on the porous $n^{+}$-GaAs substrates for development of the Gunn diodes on their basis. 


\section{Procedure of sample preparation and measurements}

For our experiments we chose GaAs three-layer MBE-grown epitaxial structures of two types, namely, (i) $n^{+}-n-n^{+}-n^{++}$-GaAs ones grown on a standard flat $n^{++}-$ GaAs substrate (samples of the type F495 - 0), and (ii) $n^{+}-n-n^{+}-n^{++}-\mathrm{GaAs}$ ones grown on a porous GaAs substrate (samples of the type F495 - 1, 2, 3).

The porous GaAs layers (the thicknesses 11 and 22 $\mu \mathrm{m})$ were obtained using electrochemical anodic pickling on the $n$-GaAs (100) substrates with the initial charge carrier concentration $n=2 \cdot 10^{18} \mathrm{~cm}^{-3}$. Water solution of hydrofluoric acid $([\mathrm{HF}]=2.3 \mathrm{M})$ with addition of potassium iodide $([\mathrm{KI}]=0.4 \mathrm{M})$ served as a electrolyte. The voltage $(12.5 \mathrm{~V})$ was applied to the cell in the pulsed mode (the frequency $2 \mathrm{~Hz}$ ). Time of etching was 20 (45) $\mathrm{s}$ for the layer thickness 11 (22) $\mu \mathrm{m}$. General degree of porosity for the layers obtained was $\sim 60 \%$; inlet density was $\sim 1 \cdot 10^{8} \mathrm{~cm}^{-2}$. The degree of porosity was determined from the data on porous layer thickness and wafer weight loss in the course of anodization. The generating pores were $100-150 \mathrm{~nm}$ in size on the surface (for inlet diameter, see Fig. 1) and 60-80 nm in the bulk of porous layer. The direction of pore intergrowth and branching was $\langle 111\rangle$ A. Due to the intense branching the initial pore channels and reflection of pores (moving from the crystal bulk toward a surface) from the space charge layer near the surface, a thin (50-80 nm) crystal region with low pore density appears in immediate neighborhood of the porous layer surface. This "quasicontinuous" layer serves as growth surface in the course of epitaxial layer growing.

The growth experiments were performed using a plant ЭП1203. It involved two high-vacuum chambers: for growth and reloading. The growth chamber had (i) eight molecular sources with conical crucibles (made of pyrolytic boron nitride) equipped with separate dampers

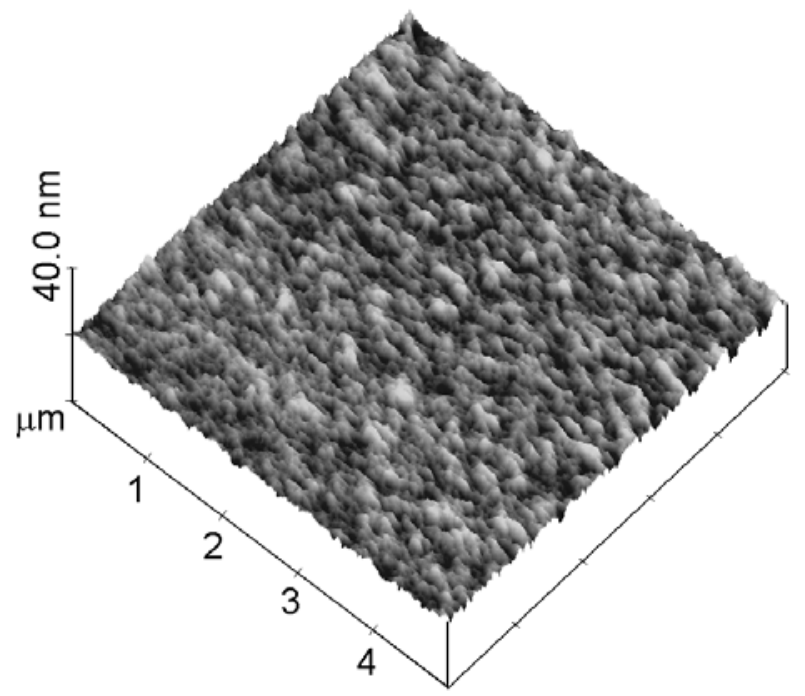

Fig. 1. Surface morphology of porous $n-n^{+}-\mathrm{GaAs}$ substrate. (overlap time of about $0.1 \mathrm{~s}$ ) and surrounded with a cryopanel cooled with liquid nitrogen; (ii) sample heater; (iii) mass spectrometer MC 7301 (measured mass range 0-300) with a high-energy electron diffractometer ДЭ1201 (incident beam energy in the $10-25 \mathrm{kV}$ range at the angle of incidence onto the sample surface of $0-4^{\circ}$ ). Each of the molecular sources was loaded with highpurity $(6 \mathrm{~N}-7 \mathrm{~N})$ materials of a single element of the Periodical Table (As, Ga, Al, In, Si, Be). This ensured supply of single atomic/molecular flows to the substrate, the overlap time being much below the typical time of MBE-deposition of one monolayer. The plant ЭП1203 was equipped with a highly efficient four-stage evacuation system, so that the residual gas pressure (after plant annealing up to the temperature $200^{\circ} \mathrm{C}$ ) was at the level of $<1 \cdot 10^{-8} \mathrm{~Pa}$.

Growth of device structures was made concurrently on the rigid and porous $n$-GaAs (100) substrates that were fixed (with indium) on a molybdenum holder. Removal of an oxide layer was made using two stages. At first, the sample temperature $T_{s}$ was increased up to $450{ }^{\circ} \mathrm{C}$ with further keeping for $20 \mathrm{~min}$ to remove remaining water from the pores. After this, $T_{s}$ was increased up to the temperature of oxide removal $\left(630^{\circ} \mathrm{C}\right)$ and remained at that level for $30 \mathrm{~min}$. Growth of structure was performed at $T_{s}=580{ }^{\circ} \mathrm{C}$. The structure involved successively sputtered $0.5 \mu \mathrm{m}$ layers of $\mathrm{GaAs}$ doped with silicon $\left(n=2 \cdot 10^{18} \mathrm{~cm}^{-3}\right)$. In the course of growth, the sample holder was rotated to increase the degree of growing layer uniformity.

The doping profiles of the grown epitaxial layers were estimated by measuring and analyzing the $C-V$ curves at the Schottky contact electrolyte-semiconductor, with alternation of processes of electrolytic etching GaAs - the technique of electrochemical voltage-capacitance (EVC) profiling. For these measurements, we used a plant PN 4200 produced by Polaron Equipment Ltd. The plant made it possible to measure concurrently the capacitance $C$ and its derivative with respect to the voltage, $d C / d V$.

$10 \%$ tiron solution in deionized water served as electrolyte. It was used both as etchant and an electric contact when taking the $C-V$ and $I-V$ curves.

The degree of sample structure perfection was estimated from the results of X-ray diffraction (XRD) measurements. The two-crystal XRD curves in the $(\theta$, $2 \theta)$ geometry and rocking curves near the GaAs (004) and $\mathrm{GaAs}$ (311) reflections were obtained using $\mathrm{Cu}_{\mathrm{K1}^{-}}$ radiation (the wavelength $\lambda=1.5406 \AA$ ); its monochromatization was made with Ge (001) crystal.

Surface morphology of the grown epitaxial layers and chips were studied using electron microscopy. Table 1 presents the results obtained for the GaAs epitaxial layers and epiready substrate.

The Gunn diodes were fabricated as forward mesa on the epitaxial structures obtained (Fig. 2). The ohmic contacts were formed on the basis of $\mathrm{Au}-\mathrm{Ge}$ eutectic with a buffer layer of amorphous nanocrystalline $\mathrm{TiB}_{x}$ 
with further gilding [7]. The forward mesa diameter was $40 \mu \mathrm{m}$. Contact resistivity was $<10^{-5} \mathrm{Ohm} \cdot \mathrm{cm}^{2}$. The Gunn diode chips were mounted in the microwave diode packages. Microwave oscillations were measured at the first and second harmonics, in the 44-59 and 101-104 $\mathrm{GHz}$ frequency ranges.

The oscillator for measurements of microwave diode parameters was a rectangular $(1.2 \times 2.4 \mathrm{~mm})$ waveguide $(78-118 \mathrm{GHz}$ frequency range) or a waveguide with a short-circuiting plunger $(40-78 \mathrm{GHz}$ frequency range). The rectangular waveguide was connected to a coaxial waveguide in the H-plane. The central conductor of the coaxial waveguide is a filter that locks the second harmonic. The coaxial waveguide is connected to the cavity resonator and is loaded with a matched load. The Gunn diode, coaxial waveguide and cavity resonator make an oscillator at the first harmonic. The second harmonic energy was removed with the rectangular waveguide. Tuning the oscillator was made by choosing the Gunn diode operating mode, the distance between the Gunn diode and cavity resonator and that between the Gunn diode and short-circuiting plunger.

\section{Experimental results and discussion}

An analysis of the XRD results obtained in the symmetric geometry near the (004) reflection showed the following:

1. GaAs layer on the epiready substrate, sample F495-0 (Fig. 3). On the diffraction curve in the $(\theta, 2 \theta)$ geometry, the peak from the GaAs layer on the epiready substrate is not separated from the substrate peak. One can see on the XRD pattern only one peak that is broadened (as compared to the case of the uncoated epiready substrate - see Fig. 4). This diffraction peak is slightly asymmetric: its slope from the side of smaller angles $2 \theta$ is more flat. This fact enables one to decompose it in two Gaussians, one of which (smaller values of the angle $2 \theta$ ) has half-width of 21 arc seconds, while for the another one it is 10 arc seconds. The halfwidth of the second peak (the bigger values of the angle $2 \theta$ ) is close to the full width at half maximum (FWHM) of the uncoated epiready substrate. Similar procedure

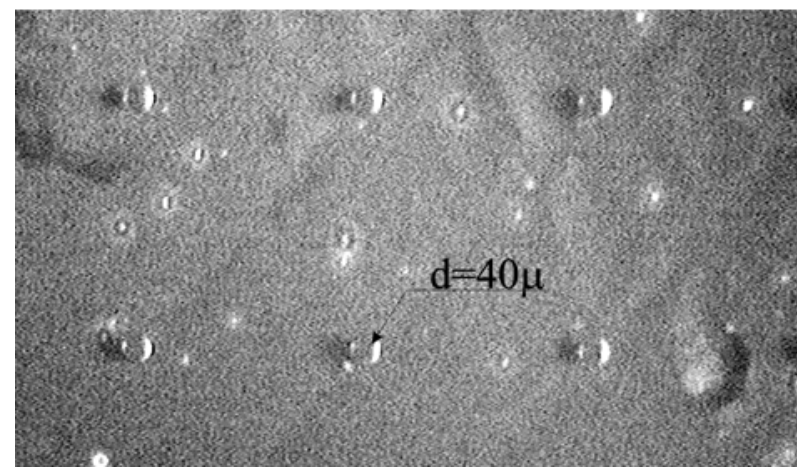

Fig. 2. Forward mesas of the Gunn diodes formed on porous GaAs substrate. was made for the $\omega$-curve. The obtained results are in good agreement with those on $(\theta, 2 \theta)$ scanning. This fact enables one to consider the above decomposition as reliable and to use the results obtained for comparison with the data got for other samples.
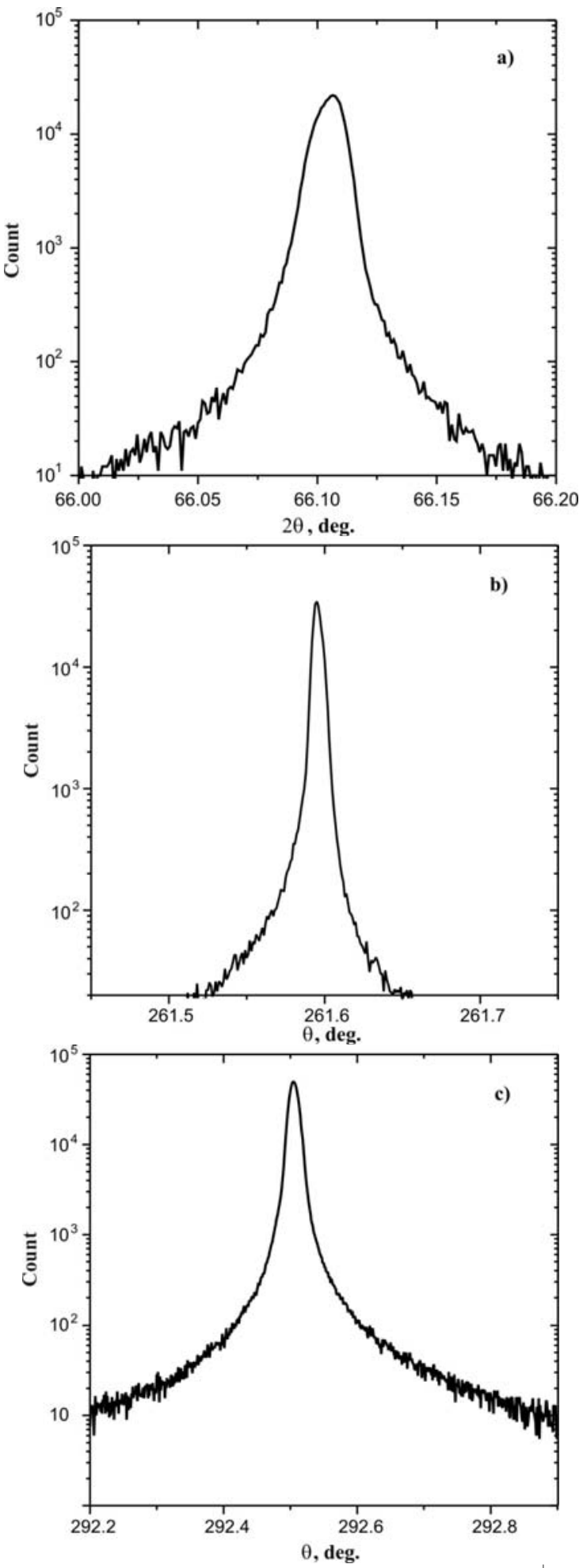

Fig. 3. X-ray diffraction curves for the sample F495-0 $\left(n^{+}-n-\right.$ $n^{+}-n^{++}$-structure grown on flat GaAs substrate) near the GaAs (004) reflection $(a, b)$ and GaAs (311) reflection (c). 

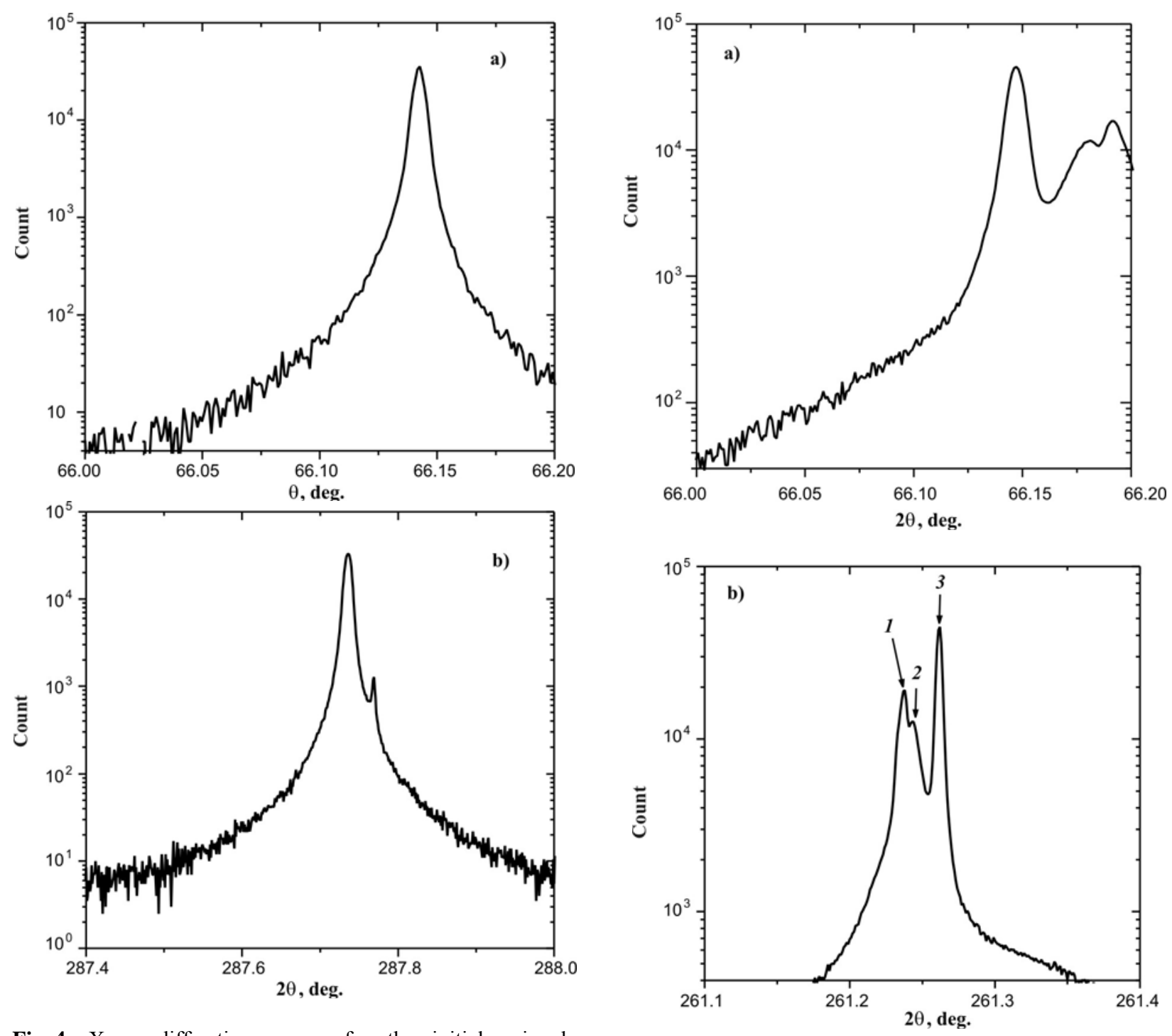

Fig. 4. X-ray diffraction curves for the initial epiready substrate near the GaAs (004) reflection (a) and GaAs (311) reflection (b).

2. One can see three peaks on the diffraction curve taken for the GaAs layers grown on porous GaAs substrates (samples F493-1-1, F493-2 and F495-3). A typical XRD pattern is shown in Fig. 5 (sample F495-2). As the angle $2 \theta$ grows, the peaks are located as follows: the first peak (3) from the GaAs epitaxial layer, the second peak (2) - from the GaAs substrate bulk, and the third peak (1) - from the layer on the porous GaAs surface or porous layer proper on GaAs surface with the smallest parameter (the numbers in parentheses correspond to those in the figures).

For the sake of more reliable interpretation of the origin of diffraction peaks, we studied porous substrate without an epitaxial layer (Fig. 6). Two peaks are observed on the diffraction curve of porous GaAs: a "narrow" peak from the bulky material and a broader one (at bigger values of the angle $2 \theta$ ) from a layer on the porous region surface. The peak regions are on a wide "pedestal" whose appearance is due to diffuse scattering at micropore boundaries.

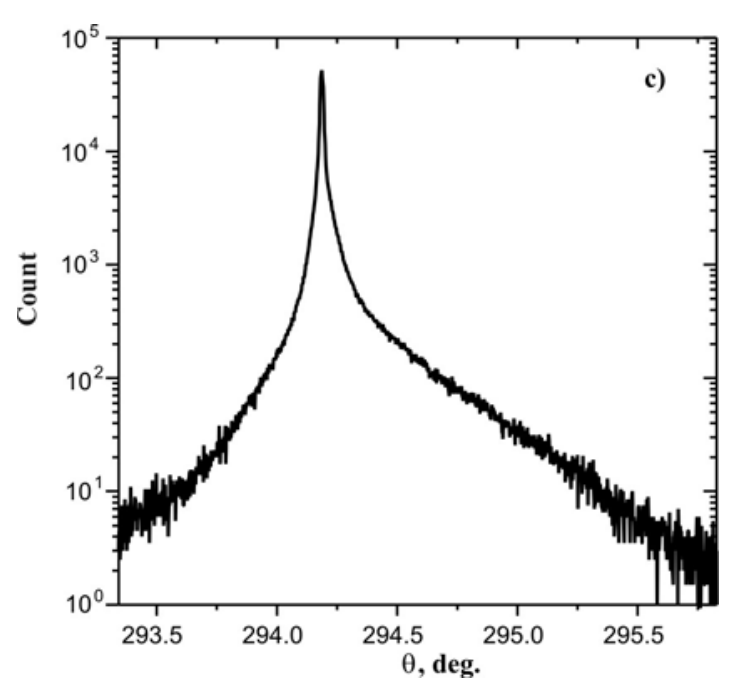

Fig. 5. X-ray diffraction curves for the sample F495-2 $\left(n^{+}-n-\right.$ $n^{+}-n^{++}$-structure grown on porous $n^{++}$-GaAs substrate) near the GaAs (004) reflection $(a, b)$ and GaAs (311) reflection (c): 1 porous GaAs; 2 - GaAs bulk; 3 - epitaxial layer. 

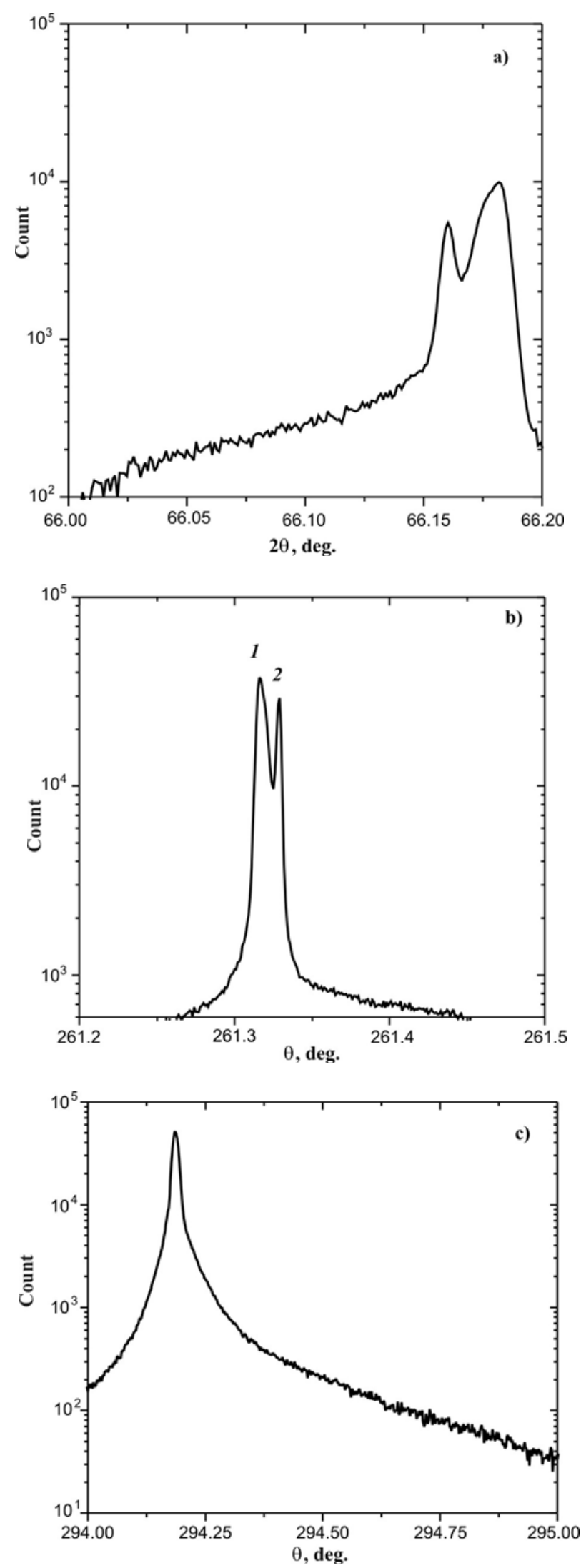

Fig. 6. X-ray diffraction curves for porous $n^{++}$-GaAs substrate near the GaAs (004) reflection (a, b) and GaAs (311) reflection (c): 1 - porous GaAs; 2 - GaAs bulk.
An analysis of the obtained results showed that the epitaxial layer grown on the epiready substrate has practically (within the instrument accuracy) no mismatch with it. The epitaxial layers on porous GaAs have the same mismatch of parameters $\left(\Delta a / a \sim 1 \cdot 10^{-3}\right)$ for all the samples studied. The half-widths of diffraction peaks are different for different samples (including the layer on the single-crystalline substrate) - see Table 1 .

One should note the difference between the FWHM values for the $(\theta, 2 \theta)$ - and $\omega$-curves for GaAs layers on porous substrates. This fact indicates possible anisotropy of the sizes of coherent scattering regions near the interface. To detect possible distinctions in the nearsurface regions of epitaxial layers, we obtained diffraction curves near the GaAs (311) reflection for the epiready substrate, GaAs layer on single-crystalline substrate, and a sample on porous substrate (Figs 4b, 3c, and $5 \mathrm{c}$, respectively).

One can see clearly from Table 1 that FWHM value is minimal for the epiready substrate and is practically the same for the epitaxial layers, whatever the type of substrate. This is a predictable result, because of the effect of substrate levels at such big layer thickness.

Investigations of the ECV profile obtained for the structure F495-0 showed that there is a small dip in the free charge carrier concentration at a depth of $\sim 2.8 \mu \mathrm{m}$ from the surface. This dip is related to presence of defects at the metallurgical boundary "epitaxial layersubstrate". The total thickness of the $n$-GaAs epitaxial layer is $2.8 \mu \mathrm{m}$. Our measurements showed that the upper and lower $n^{+}$-GaAs contact layers are about $0.4 \mu \mathrm{m}$ thick and are doped with $\mathrm{Si}$ (at a level of $\left.2 \cdot 10^{18} \mathrm{~cm}^{-3}\right)$. The thickness of the region of low doping level (calculated from the ECV profile) is about $2 \mu \mathrm{m}$, while the electron concentration lies between $1 \cdot 10^{16}$ and $8 \cdot 10^{15} \mathrm{~cm}^{-3}$.

The ECV profile of the structure F495-3 demonstrates the same parameters of the upper contact layer and weakly doped region in $n$-GaAs as those corresponding to the profile of the structure F495-0.

Table 1. Half-widths of $\mathrm{X}$-ray diffraction peaks (in arc seconds) for the samples studied.

\begin{tabular}{|l|c|c|c|c|}
\hline \multicolumn{1}{|c|}{ Sample } & \multicolumn{3}{|c|}{$(004)$} & $(311)$ \\
\cline { 2 - 5 } & $\begin{array}{c}\text { FWHM } \\
2 \theta\end{array}$ & $\begin{array}{c}\text { FWHM } \\
\omega\end{array}$ & $\delta \theta$ & FWHM $\omega$ \\
\hline $\begin{array}{l}\text { Epiready GaAs } \\
\text { substrate }\end{array}$ & 8 & - & - & 35 \\
\hline $\begin{array}{l}\text { GaAs/ GaAs(mono) } \\
\text { F495-0 }\end{array}$ & 21 & 22 & 0 & 52 \\
\hline $\begin{array}{l}\text { GaAs/ GaAs(por) } \\
\text { F495-1-1 }\end{array}$ & 16 & 20 & $\begin{array}{c}(2)-(3) \\
64\end{array}$ & - \\
\hline $\begin{array}{l}\text { GaAs/ GaAs(por) } \\
\text { F495-2 }\end{array}$ & 14 & 14 & $\begin{array}{c}(2)-(3) \\
64\end{array}$ & 54 \\
\hline $\begin{array}{l}\text { GaAs/GaAs(por) } \\
\text { F495-3 }\end{array}$ & 26 & 29 & $\begin{array}{c}(2)-(3) \\
65\end{array}$ & - \\
\hline
\end{tabular}




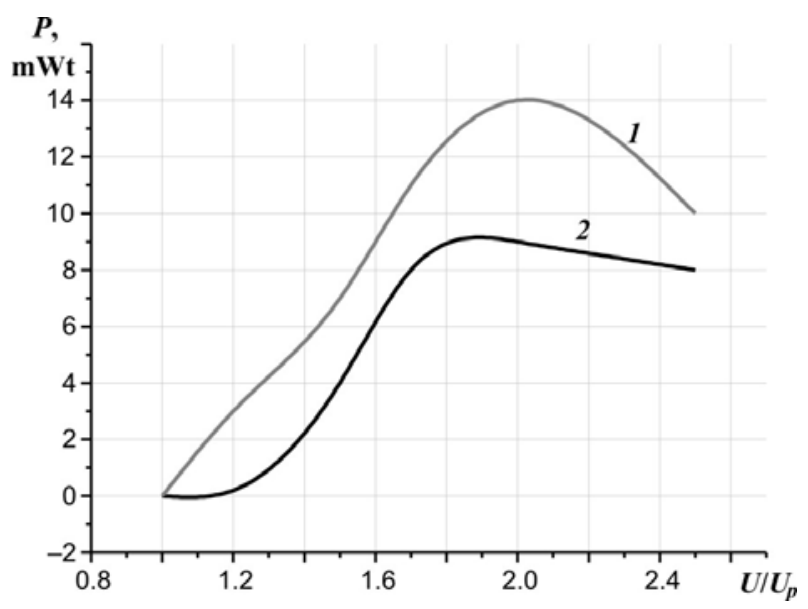

Fig. 7. Gunn diode power output as a function of the relative bias voltage (forward mesas; frequency $f=44 \mathrm{GHz}$ ): 1 - "soft" substrate; 2 - standard substrate.

However, the boundary between the weakly doped region and the lower contact layer is smeared out considerably, contrary to the profile of the structure F495-0, and the free charge carrier concentration value achieves $7 \cdot 10^{19} \mathrm{~cm}^{-3}$ at the depth of $3.6 \mu \mathrm{m}$. This is much over the substrate doping level. Such behavior of the ECV profile of the structure F495-3 may be related to the fact that a porous layer was formed on the $n^{+}$GaAs substrate in the course of electrochemical etching. As a result, the lower $n^{+}$-GaAs contact layer could have porous structure too. When, in the course of ECV profile measurement, electrolyte reached the lower $n$-GaAs contact layer, the area of the electrolyte-semiconductor contact increased due to presence of pores. This resulted in increase of the measured structure capacitance and, correspondingly, in increase of the concentration in the ECV profile. The porous boundary retained at etching the $n^{+}$-GaAs substrate, where the ECV profile also demonstrated concentration value over the true one. The bottom of the etching crater for the structure F495-0 is flat, while in the case of the structure F495-3 it has a very developed surface. This fact supports our assumptions.

The parameters of the Gunn diodes made on the basis of epitaxial layers MBE-grown on the standard substrates are given in Table 2. One can see that the

Table 2. The parameters of the Gunn diodes made on standard and porous GaAs substrates as forward mesas.

\begin{tabular}{|l|c|c|}
\hline \multirow{2}{*}{$\begin{array}{c}\text { Microwave parameters } \\
\text { of the Gunn diodes }\end{array}$} & \multicolumn{2}{|c|}{ Substrates } \\
\cline { 2 - 3 } & standard & porous \\
\hline Frequency $F, \mathrm{GHz}$ & $44-59$ & $44-59$ \\
\hline Power output $P, \mathrm{~mW}$ & $14-10$ & $17-12$ \\
\hline Frequency $F, \mathrm{GHz}$ & 101 & 104 \\
\hline Power output $P, \mathrm{~mW}$ & 1.8 & 3.2 \\
\hline
\end{tabular}

diodes fabricated on the epitaxial films grown on porous substrates have power output higher (by a factor of $1.2-1.3$ at the first harmonic and 1.7 at the second one) than the diodes made on the standard substrates. It was also found that the diodes on porous substrate started oscillation at operation voltages close to the threshold ones (the so-called "soft" triggering), while in the diodes made on the traditional (standard) substrates oscillation began at voltages $20 \%$ over the threshold ones ("rigid" triggering). Shown in Fig. 7 are the dependencies of the Gunn diode power output on the relative bias voltage for both above diode types. The results obtained correlate with the degree of structure perfection of the epitaxial layers grown on the porous GaAs substrates.

\section{Conclusions}

Thus, it was shown experimentally that:

- on nanostructured porous substrates made on heavily doped GaAs, single-crystalline GaAs layers are epitaxially growing, with lattice mismatch of the film and substrate $\sim 10^{-3}$;

- the Gunn diodes made on such epitaxial structures as forward mesas have better output parameters than similar diodes made on the standard (flat) GaAs, namely, their power output is higher by $20-30 \%$ (at the first harmonic) and by $70 \%$ (at the second harmonic) than for the Gunn diodes made on the standard substrates;

- the Gunn diodes made on the standard substrates demonstrate "soft" triggering into the oscillation mode.

\section{Acknowledgement}

This work was performed in the framework of the Russian-Ukrainian Program on Nanophysics and Nanoelectronics.

\section{References}

1. V.V. Mamutin, V.P. Ulin, V.V. Tret'yakov, S.V. Ivanov, S.G. Konnikov, P.S. Kop'ev, Obtaining of cubic GaN with MBE on porous GaAs substrates // Pis'ma $v$ ZhTF 26(1), p. 3-9 (1999) (in Russian).

2. F.Yu. Soldatenkov, V.P. Ulin, A.A. Yakovenko, O.M. Fedorova， S.G. Konnikov， V.I. Korol'kov, Unstressed $\operatorname{In}_{x} \mathrm{Ga}_{1-x}$ As epitaxial films obtained on porous GaAs // Pis'ma v ZhTF 25(21), p. 15-20 (1999) (in Russian).

3. M. Mynbaeva, A. Titkov, A. Kryzhanovski, I. Kotousova, A.S. Zubrilov, V.V. Ratnikov, V.Yu. Davydov, N.I. Kuznetsov, V.V. Mynbaev, D.V. Tsvetkov, S. Stepanov，A. Chernikov， V.A. Dmitriev，Strain relaxation in $\mathrm{GaN}$ layers grown on porous $\mathrm{GaN}$ sublayers // MRS Internet J. Nitride Semicond. Res. 4, p. 14-18 (1999). 
4. I.N. Arsentiev, V.M. Baydakova, A.V. Bobyl, L.S. Vavilova, S.G. Konnikov, V.P. Ulin, N.S. Boltovets, R.V. Konakova, V.V. Milenin, D.I. Voytsikhovskyi, Structural and electrical characteristics of InP epitaxial layers on porous substrates, and parameters of $\mathrm{Au}-\mathrm{Ti}$ Schottky barriers to them // Pis'ma v ZhTF 28(17), p. 57-66 (2002) (in Russian).

5. I. Shalish, Yoram Shapira, Stability of Schottky contacts with $\mathrm{Ta}-\mathrm{Si}-\mathrm{N}$ amorphous diffusion barriers and $\mathrm{Au}$ overlayers on $6 \mathrm{H}-\mathrm{SiC} / / \mathrm{J}$. Vac. Sci. Technol. B18(5), p. 2477-2481 (2000).
6. N.S. Boltovets, V.N. Ivanov, R.V. Konakova, Ya.Ya. Kudryk, O.S. Lytvyn, P.M. Lytvyn, V.V. Milenin, Interactions between phases and the features of structure relaxation in $\mathrm{TiB}_{x}-n$-GaAs $(\mathrm{InP}, \mathrm{GaP}, 6 \mathrm{H}-$ $\mathrm{SiC})$ contacts exposed to active treatments // Fiz. Tekh. Poluprov. 38(7), p. 769-774 (2004) (in Russian).

7. V.N. Ivanov, R.V. Konakova, V.V. Milenin, M.A. Stovpovoi, Contact-forming films of titanium borides and nitrides in gallium arsenide microwave devices /I Tekhnologiya $i$ Konstruirovanie $v$ Radioelektronnoi Apparature No 6, p. 54-56 (2002) (in Russian). 